\title{
Factors associated with pharmacological and psychotherapy treatments adherence in patients with Borderline personality disorder in Iran
}

\section{Motahareh Sadat Mirhaj Mohammadabadi}

Psychosocial Health Research Institute, Iran University of Medical Sciences Homa Mohammadsadeghi

Psychosocial Health Research Institute, Iran University of Medical Sciences

\section{Mehrdad Eftekhar Adrebili}

Psychosocial Health Research Institute, Iran University of Medical Sciences

\section{Zahra Partovi Kolour}

Iran University of Medical Sciences

\section{Fatemeh Kashaninasab}

Psychosocial Health Research Institute, Iran University of Medical Sciences

\section{Mohammadreza Shalbafan ( $\square$ Shalbafan.mr@iums.ac.ir)}

Psychosocial Health Research Institute, Iran University of Medical Sciences

\section{Research Article}

Keywords: Borderline personality disorder, treatment outcome, pharmacotherapy, psychotherapy

Posted Date: September 2nd, 2022

DOl: https://doi.org/10.21203/rs.3.rs-1202989/v4

License: (1) This work is licensed under a Creative Commons Attribution 4.0 International License. Read Full License 


\section{Abstract}

\section{Background}

Borderline personality disorder is a major mental illness characterized by sustained relationship instability, impulsive behavior, and intense affects. Adherence is a complex behavior, from minor refusals of treatment to abandonment of treatment, which can be affected by various factors. Therefore, the present study aimed to investigate the factors affecting pharmacological and psychotherapy adherence, patients' attitude towards medication, and assessing medication and treatment adherence in patients with borderline personality disorder referred to an outpatient referral clinic in Tehran, Iran.

\section{Methods}

The study was a retrospective cohort study. The files of patients with borderline personality disorder referred to the outpatient clinic of the Tehran Psychiatric Institute were reviewed as the first step. In the next step, we contacted the patients and asked them to fill out the questionnaires. Data were collected using the Drug Attitude Inventory-10 (DAl-10) questionnaire and a researcher-made questionnaire to determine the attitude of patients toward pharmacological and psychotherapy treatment as well as therapeutic adherence. After collecting data, patients' therapeutic adherence was divided into three groups: poor, partial, and good compliance. The data were analyzed by SPSS software version-22.

\section{Results}

Ninety-four patients were involved in the study, and fifty-four were women. In psychotherapy adherence, patients with higher education and hospital admission history have better compliance. Findings of DAI showed that 54 (57.4\%) participants had negative attitudes toward medication, while 38 (40.4\%) participants showed a negative attitude toward psychotherapy treatment. Additionally, the percentage of patients who had good psychotherapy adherence (44.7\%) was higher than that of patients with good medication adherence (31.9\%). The most common reasons for discontinuation of treatment were medication side effects (53.1\%), dissatisfaction with the therapist (40.3\%), and then fear of medication dependence (40\%). Patients with higher education level and positive history of hospitalization in a psychiatric ward had better psychotherapy adherence $(P<0.05)$.

\section{Conclusions}

Results of the current study show that attitude toward psychotherapy is more favorable than pharmacotherapy among patients with BPD. The rationale may be medications are mainly prescribed for comorbid conditions, and do not have substantial effects on the BPD symptoms, resulting in low medication adherence.

\section{Background}


Borderline personality disorder (BPD) is characterized by severe instability in impulsive feelings, identities, relationships, and behaviors (1). Patients with BPD are hypersensitive to emotional stimuli due to abnormal activity in the brain's prefrontal areas during stimulus processes (2). BPD is a major mental illness that has a prevalence of approximately $1-3 \%$ among the general population. Instability of relationships, the creation and regulation of impulses, and the sense of life were some of the main features of the disorder (3). BPD is a severe disorder that accounts for 20 to $40 \%$ of psychiatric admissions, and it is estimated that $84 \%$ of patients show suicidal behaviors, and $8 \%$ of them die due to suicide $(4,5)$. BPD causes many problems for the patient and the community. The repeated and severe damages caused by this disorder affect an individual's entire life, including occupational problems, being a dropout, and disruption of relationships with friends and colleagues, family members, failure in marriage, and high-risk and unstable sexual relations. Almost $11-69 \%$ of patients are substance users, $22 \%$ suffer from alcoholism, and 25 to $50 \%$ of female prisoners are patients with BPD (6-11).

An accurate prevalence rate is not available in Iran. Due to the cultural and civil context in Iran, and the existence of religious thoughts in the Iranian community and families, in most cases, some behaviours of patients with BPD, such as extramarital relationships and substance use, are contrary to social norms and severely complicate among Iranian society $(12,13)$.

In a study by Bellino et al., patients with more severe BPD and higher levels of symptoms such as fear of abandonment, emotional instability, and identity showed a better chance of combining psychotherapy with fluoxetine (14). Although psychotherapy is still the first line of treatment for patients with BPD, medications are commonly prescribed for them. The use of antidepressants has decreased, and mood stabilizers and second-generation antipsychotics have increased (15).

Adherence is a complex behavior, from minor refusals of treatment to abandonment of therapy, which can be affected by various factors(16). Rejection of treatment is often associated with irrational fears and misjudgments, and the most common cause is fear of medication dependence. Various studies have been performed on patients with personality disorders, schizophrenia, and bipolar, showing that one of the critical issues in the treatment is the adherence to treatment by patients. Due to the prevalence of BPD and the need for long-term pharmacological and psychotherapy treatment, the high cost of treatment imposed on the health care system, and the fact that no study was conducted in Iran, it seems necessary to evaluate the medication and psychotherapy adherence in these patients. Hoping that by working on changeable factors, patients' adherence and, consequently, their function improves, and the recurrence of symptoms and re-admission will be reduced.

In the present study, we investigate the factors of rejection and reasons for discontinuation of treatment, more specifically psychotherapy as the first-line treatment of BPD, to provide a way to improve adherence in these patients and to introduce practical methods into the clinical practice of therapists in future studies.

\section{Methods}




\section{Study design \& Participants}

The study was conducted as a retrospective cohort study. In this study, the files of patients with BPD who were referred to the outpatient adult psychiatric clinic of Tehran Psychiatric Institute, Tehran, Iran, from April 2014 to April 2019 were reviewed as the first step. Patient information includes name, gender, age, occupation, education, marital status, family history of psychiatric illness, type of treatment, history of substance use, history of hospitalization, history of suicide and self-harm, comorbidity, and medication side effects on the files, was recorded. In the next step, patients were contacted to collect the information, including receiving or not receiving medical or psychotherapy treatment, last referral date, confirmation of demographic data, current life status (alone, with family), suicide and self-harm, financial status, legal issues, medication side effects, and location (far or close to the treatment center). In addition, they were asked to fill out the Drug Attitude Inventory (DAl) questionnaire and a researcher-made questionnaire to determine the attitude of patients toward pharmacological and psychotherapy treatment and therapeutic adherence. Patients who did not respond were called three times within a week, and if they did not respond, they were given a message and excluded from the study if they did not respond again.

\section{Instruments}

In addition to demographic items, two questionnaires were used in this study. The first questionnaire, was DAl-10 based, which evaluates the attitude of patients toward medication with 10 yes-no questions, and a higher total score between +10 and -10 shows a more positive attitude. Shariati et al. confirmed the psychometric properties of the Persian version of the scale (17). They reported that Test-retest reliability was 0.805 and Cronbach's a 0.787 . Concurrent validity between the DAl-10 score and Medication possession rate (MPR) at the study time was 0.676 , and the positive predictive value of the DAl-10 score for medication compliance at assessment time was about $88.9 \%$. The Spearman correlation coefficient between the two tests was 0.822 (95\% confidence interval (Cl): $(0.652-0.901)$ ). They also reported a cutoff point +1 , with a specificity of $81.5 \%$ and a sensitivity of $89.1 \%$. (17).

Additionally, based on the participants' reports, the researcher evaluated the patients' current medical adherence, and according to the MPR, patients were divided into three groups: poor, good, and partial pharmacological adherence. Based on MPR more than $80 \%$ equal good adherence, between 50 to $80 \%$ equal partial adherence, and less than $50 \%$ equal poor adherence. In our study last month, the MPR represents the proportion of days of medication supply in a specified period and is given by the sum of days divided by the number of days within the time interval $(18,19)$. In addition, based on the participant's report and documented visits for psychotherapy sessions, the psychotherapy adherence of the patients was evaluated. The division into poor, partial, and good psychotherapy adherence is based on the percentage of on-time performed sessions to proposed sessions by the therapist in the last month, and the cut-offs were similar to MPR.

To the best of our knowledge, there is no comprehensive validated Persian questionnaire to evaluate the attitude of patients toward medication and psychotherapy treatment and reasons for poor/partial drug compliance. Therefore, the second questionnaire was a researcher-made questionnaire to determine the 
attitude of patients toward pharmacological and psychotherapy treatment and therapeutic adherence. This questionnaire consisted of 17 questions that were developed by the authors and validated by eight psychiatric faculty members of the Iran University of Medical Sciences. To standardize and validate the questionnaire, a qualitative assessment was done using an expert panel, and a quantitative assessment was done using content validity ratio (CVR) and content validity index (CVI) (20). According to the overall CVR $(0.75<)$ and the CVI $(0.79<)$, the questionnaire had content validity. This questionnaire was divided into two parts to emphasize reasons for poor/partial medication compliance. The first part, which included questions (1-6), was filled by all 94 patients, and if the participants' medication adherence were poor/ partial, based on MPR, they were asked to fill the second part (questions 7-17). Therefore, 64 patients filled the second part of the questionnaire.

All questionnaires were filled out, and evaluations were performed for each participant on the same day.

\section{Statistical analysis}

Data were analyzed by IBM SPSS STATISTICS 22(IBM Inc, New York, USA). Data are presented as numbers and percentages and compared between groups by chi-square and t-test. Patients' outcome was statistically analyzed based on variables using the Kaplan method. P values less than 0.05 were assumed as statistically significant. Type I error (alpha) is set at $5 \%$.

\section{Results}

Ninety-four patients were involved in the study; the mean age was 33.6, 54 (57.4\%) were female, and the others were male. Demographic data, medication and psychotherapy adherence, and psychiatric history of the participants are shown in Tables 1-3. 
Table 1

Demographic data of participants

\begin{tabular}{|lll|}
\hline Variable & & Frequency (\%) \\
\hline Employment & Employed & $41(43.6)$ \\
& College students & $10(10.6)$ \\
& Unemployed & $43(45.7)$ \\
\hline Education & Under diploma & $21(22.3 \%)$ \\
\hline & Diploma and higher & $43(45.8)$ \\
\hline \multirow{2}{*}{ Marital status } & Bachelor's degree & $21(22.3 \%$ \\
& Single & $9(9.6 \%)$ \\
\hline & Married & $49(52.1 \%)$ \\
& Divorced & $32(34 \%)$ \\
\hline
\end{tabular}

Table 2

Medication and psychotherapy adherence of participants

\begin{tabular}{|lll|}
\hline Variable & & Frequency (\%) \\
\hline Medication Adherence & Poor & $46(48.9 \%)$ \\
\hline & Moderate & $18(19.1 \%)$ \\
\hline & Good & $30(31.9 \%)$ \\
\hline Psychotherapy Adherence & Poor & $21(22.3 \%)$ \\
\hline & Partial & $31(33 \%)$ \\
\hline & Good & $42(44.7 \%)$ \\
\hline
\end{tabular}


Table 3

Participants' psychiatric history

\begin{tabular}{|ll|}
\hline History & Frequency (\%) \\
\hline Psychiatric Hospitalization & $21(22.3 \%)$ \\
\hline Family history of psychiatric illness & $34(36.2 \%)$ \\
\hline Legal problems & $15(16 \%)$ \\
\hline Self-injury & $30(31.9)$ \\
\hline Suicide attempt & $40(42.6)$ \\
\hline Illegal substance use & $42(44.7)$ \\
\hline
\end{tabular}

Answers to the researcher-made questionnaire about the attitude of patients toward pharmacological and psychotherapy treatment and therapeutic adherence are shown in Table 4, and reasons for poor/partial drug compliance are shown in Table 5.

Table 4

Insight and attitude toward treatment (First part of the questionnaire)

\begin{tabular}{|c|c|c|c|}
\hline Number & Questions & Answer & $\begin{array}{l}\text { Frequency } \\
(\%)\end{array}$ \\
\hline \multirow[t]{2}{*}{1} & \multirow[t]{2}{*}{ I am sick and need treatment } & Yes & $65(69.1)$ \\
\hline & & No & $29(30.9)$ \\
\hline \multirow[t]{2}{*}{2} & \multirow{2}{*}{$\begin{array}{l}\text { Lack of treatment can disrupt my life and the lives of those } \\
\text { around me }\end{array}$} & Yes & $59(62.8)$ \\
\hline & & No & $35(37.2)$ \\
\hline \multirow[t]{2}{*}{3} & \multirow{2}{*}{$\begin{array}{l}\text { Lack of treatment can cause problems in my relationships } \\
\text { with others }\end{array}$} & Yes & $67(71.3)$ \\
\hline & & No & $27(28.7)$ \\
\hline \multirow[t]{2}{*}{4} & \multirow[t]{2}{*}{ My illness is treatable } & Yes & 73(77.7) \\
\hline & & No & $21(22.3)$ \\
\hline \multirow[t]{2}{*}{5} & \multirow[t]{2}{*}{ Medication has not helped my condition } & Yes & $49(52.1)$ \\
\hline & & No & $45(47.9)$ \\
\hline \multirow[t]{2}{*}{6} & \multirow[t]{2}{*}{ Psychotherapy or counselling did not help my condition } & Yes & $38(40.4)$ \\
\hline & & No & $56(59.6)$ \\
\hline
\end{tabular}


Table 5

Reasons for poor/partial medication adherence (Second part of the questionnaire)

\begin{tabular}{|c|c|c|c|}
\hline Number & Questions & Answer & $\begin{array}{l}\text { Frequency } \\
\text { (\%) }\end{array}$ \\
\hline \multirow[t]{2}{*}{1} & \multirow{2}{*}{$\begin{array}{l}\text { I did not continue the treatment due to the cost of the doctor's } \\
\text { visit. }\end{array}$} & Yes & 12(18.8) \\
\hline & & NO & $52(81.2)$ \\
\hline \multirow[t]{2}{*}{2} & \multirow[t]{2}{*}{ I did not go to another center due to travel expenses. } & Yes & $10(15.6)$ \\
\hline & & NO & $54(84.4)$ \\
\hline \multirow[t]{2}{*}{3} & \multirow{2}{*}{$\begin{array}{l}\text { Because I was not satisfied with my doctor, I did not see him } \\
\text { again. }\end{array}$} & Yes & $26(40.6)$ \\
\hline & & NO & $38(59.4)$ \\
\hline \multirow[t]{2}{*}{4} & \multirow{2}{*}{$\begin{array}{l}\text { Because I could not easily make an appointment, I did not } \\
\text { return. }\end{array}$} & Yes & $18(28.1)$ \\
\hline & & NO & $46(71.9)$ \\
\hline \multirow[t]{2}{*}{5} & \multirow{2}{*}{$\begin{array}{l}\text { The misbehavior of others and their talk about my illness } \\
\text { caused me to stop taking my medication. }\end{array}$} & Yes & 12(18.8) \\
\hline & & NO & $52(81.3)$ \\
\hline \multirow[t]{2}{*}{6} & \multirow[t]{2}{*}{ Medication side effects caused me to stop my medication. } & Yes & $34(53.1)$ \\
\hline & & NO & $30(46.9)$ \\
\hline \multirow[t]{2}{*}{7} & \multirow{2}{*}{$\begin{array}{l}\text { I stopped taking the medication because of the cost of the } \\
\text { medication. }\end{array}$} & Yes & 13(20.3) \\
\hline & & NO & $51(79.7)$ \\
\hline \multirow[t]{2}{*}{8} & \multirow{2}{*}{$\begin{array}{l}\text { Because the duration of my medication was long, I did not take } \\
\text { any more medications. }\end{array}$} & Yes & $21(32.8)$ \\
\hline & & NO & $43(67.2)$ \\
\hline \multirow[t]{2}{*}{9} & \multirow[t]{2}{*}{ I stopped taking it for fear of medication dependence. } & Yes & $26(40.6)$ \\
\hline & & NO & $38(59.4)$ \\
\hline \multirow[t]{2}{*}{10} & \multirow[t]{2}{*}{ I stopped psychotherapy due to the cost of psychotherapy. } & Yes & $21(32.8)$ \\
\hline & & NO & $43(67.2)$ \\
\hline \multirow[t]{2}{*}{11} & \multirow{2}{*}{$\begin{array}{l}\text { Long-term psychotherapy was the reason for interrupting } \\
\text { psychotherapy sessions }\end{array}$} & Yes & 13(20.3) \\
\hline & & NO & $51(79.4)$ \\
\hline
\end{tabular}

Moreover, regarding the DAl-10 total score, 54 patients (57.4\%) had a negative attitude, and 40 patients (42.6\%) had a positive attitude towards the medication.

There was no relationship among gender $(P=0.33)$, job $(P=0.16)$, education $(P=0.71)$, marital status ( $P$ $=0.37)$, history of psychiatric hospitalization $(P=0.81)$, history of self-injury $(P=0.83)$, suicide history $(P$ 
$=0.54)$, history of substance use $(P=0.85)$, comorbidity with psychiatric disorders $(P=0.63)$, family history of mental illness $(P=0.77)$ and medication adherence.

There was no relationship among gender $(P=0.62)$, job $(P=0.30)$, marital status $(P=0.75)$, history of self-injury $(P=0.36)$, suicide history $(P=0.64)$, history of substance use $(P=0.57)$, comorbidity with psychiatric disorders $(P=0.23)$, family history of mental illness $(P=0.52)$ and type of medication used ( $=0.06)$ and psychotherapy adherence. There was a statistically significant relationship between education level and psychotherapy adherence $(P=0.02)$. The best adherence to psychotherapy was obtained in postgraduate education (with $66 \%$ good adherence among this subgroup) and the worst medication adherence in undergraduate education (with $22 \%$ good adherence among this subgroup) $(P=$ 0.04). In terms of the history of the psychiatric hospitalization, it has a significant relationship with psychotherapy adherence $(P=0.01)$; those who had a history of hospitalization had better adherence to psychotherapy than non-hospitalized patients ( $66 \%$ vs. $36.9 \%$ of the relevant subgroup).

Based on the results, patients' belief that their disorder is treatable, lack of treatment disrupts their lives, and those around them are inversely related to poor and relative medication adherence. Patients with a negative medication attitude are 1.3 times more likely to have poor medication adherence and 2.8 times more likely to have relative medication adherence. Our finding revealed that patients with postgraduate education are 2.2 times more likely to have good psychotherapy adherence.

There was a significant relationship between attitudes toward medication and the belief that "lack of treatment disrupts relationships with others". $87.5 \%$ of patients with a positive attitude stated that lack of treatment could disrupt their relationships with others. $81.5 \%$ of patients who disagreed with this view had a negative medication attitude $(P=0.03)$. There was a significant relationship between attitudes toward medication and the belief that "their disorder can be treated". $95 \%$ of patients with a positive medication attitude believed that their disorder could be treated $(P=0.001) .72 .2 \%$ of patients who had a negative attitude toward medication, believed that its side effects had interrupted their treatment $(P=$ 0.02).

\section{Discussion}

This study aimed to determine the factors contributing to the pharmacological and psychotherapy adherence in 94 patients with BPD, who were referred to the outpatient clinic of Tehran Psychiatric Institute. This study showed that gender, occupation, education, marriage, history of psychiatric hospitalization, history of self-harm and suicide attempt, and history of substance use had no significant relationship with medication adherence. However, education and history of hospitalization were significantly higher in patients with good, adherence to psychotherapy. Also, the analysis showed that there was no significant relationship between gender, occupation, education, marriage, history of psychiatric hospitalization, history of self-harm and suicide, and history of drug use and adherence to medication. 
In 2020, Zarei et al. examined BPD improvement at different time intervals of transference-focused treatment. Their findings showed that gender, occupation, education, marriage, history of psychiatric hospitalization, and the history of self-harm had no significant relationship with adherence to treatment, which was consistent with our results (21). In another study, there was no significant relationship between the history of self-harm, substance use, psychiatric comorbidity, history of psychiatric illness, and type of medication and medication adherence that was consistent with our results (22).

In a study among soldiers, Soltaninejad et al. showed that in patients with BPD, self-injury, substance use, psychiatric comorbidity, history of psychiatric illness, and type of pharmacotherapy had no significant relationship with adherence to medication that was consistent with our results (23).

The findings of our study showed better attitudes toward psychotherapy than medication. On the other hand, negative attitudes toward medication, and fear of medication dependence were the most common reason for poor medication adherence. In addition, $42.6 \%$ of participants had positive attitudes toward medications in the current study, and $31.9 \%$ had good medication adherence. It's lower than the percentage with the same scales, DAl-10 and MPR, among some other psychiatric patients. Asadi et al. reported that more than $85 \%$ of participants had positive attitudes toward medication and more than $55 \%$ had good medication adherence among Iranian male patients with the methamphetamine-induced psychotic disorder in a three-month follow-up study after discharge from a mental hospital (18). Similarly, Azadforouz et al. also reported that $63.8 \%$ of patients with bipolar I disorder had good medication adherence in a 6-month follow-up study in Iran (24). A plausible rationale for lower medication adherence and less positive attitude toward medication among patients with BPD is the lack of substantial effectiveness of medications in this disorder, and probably lack of positive previous experience with medication which is not proven for BPD, despite pharmacotherapy is still highly prevalent in the management of the patients (25). These findings emphasize the importance of psychotherapeutic approaches for managing patients with BPD as a more effective and accepted treatment method than pharmacotherapy.

\section{Limitations}

There were several limitations; the first one was the small sample size. Also, some inaccurate recording of documents, the lack of facilities to follow up with patients, and failure to assess the severity of the disorder were other limitations. In addition, the lack of a control group is another limitation of the current study. The nature of the study and retrospective gathering of a part of the data could be pointed to as other limitations of the study. Moreover, our findings cannot show a causality effect between psychosocial variables and main outcomes.

It is suggested to consider these limitations for future studies and performing a multi-centered study with the control group, follow-up, and evaluation of the severity of symptoms. Further evaluation of the psychometric properties of the researcher-made questionnaire is also recommended. Future studies on interventions to improve psychotherapy adherence are suggested too. 


\section{Conclusions}

In conclusion, the findings of the current study showed that most patients with BPD had negative attitudes toward medication and medication adherence among them was lower than psychotherapy adherence. The rationale may be that medications are mainly prescribed for other comorbid conditions, and do not substantially affect the BPD symptoms, resulting in low medication adherence.

We also found that the education level of the patients had a positive relationship with good psychotherapy adherence. Therefore, patients with lower education levels should be followed-up by the healthcare providers to prevent discontinuation of their psychotherapy sessions.

Overall, the findings emphasize the importance of psychotherapy, as the first-line treatment approach, among patients with BPD and suggest future studies on interventions to improve psychotherapy adherence of the patients.

\section{Abbreviations}

Borderline personality disorder

BPD

Drug Attitude Inventory

DAI

Medication possession rate

MPR

content validity ratio

CVR

content validity index

CVI

\section{Declarations}

\section{Funding}

This research received no specific grant from any funding agency in the public, commercial, or not-forprofit sectors.

\section{Competing interests}

The authors have no conflicts of interest to report.

\section{Availability of data and materials}

The datasets generated and/or analysed during the current study are not publicly available due to confidentiality concerns (in the informed consent, we have committed to the participants to publish only 
the general and group results of the study). Still, they are available from the corresponding author on reasonable request.

\section{Authors' contributions}

Conceptualization and design: MSMM, HM, MEA and MS; Data gathering: MSMM, ZPK, FK; Initial draft preparation: MSMM, HM and MS; Editing \& review: All authors. All authors read and approved the final manuscript.

\section{Ethics approval}

In this study, no intervention was performed on patients. If a person refused to participate in the study, they wouldn't be deprived of any medical services. All personal information remained confidential. The study protocol was approved by the Institutional Review Board of Iran University of Medical Sciences (Ethic code: IR.IUMS.FMD.REC.1397.193) and conducted according to the Declaration of Helsinki, subsequent revisions, and other relevant guidelines and regulations.

\section{Consent to participate}

Online informed consent was taken from the patients.

\section{Consent for publication}

Not applicable

\section{Acknowledgment}

We wish to thank the outpatient psychiatric clinic of Tehran Psychiatric Institute, which helped us complete this dissertation.

\section{References}

1. Falconer CJ, Cutting P, Bethan Davies E, Hollis C, Stallard P, Moran P. Adjunctive avatar therapy for mentalization-based treatment of borderline personality disorder: a mixed-methods feasibility study. Evid Based Ment Health. 2017 Nov;20(4):123-127.

2. Lischke A, Herpertz SC, Berger C, Domes G, Gamer M.Divergent effects of oxytocin on (para-) limbic reactivity to emotional and neutral scenes in females with and without borderline personality disorder. Soc Cogn Affect Neurosci. 2017 Sep 19

3. Bassir Nia A, Evel eth MC, Gabbay JM, Hassan YJ, Zha ng B, Perez-R odriguez MM Past, present, and future of genetic research in borderline personality disorder. Curr Opin Psychol. 2017 Sep 12;21:6068.

4. Kaplan BJ. Kaplan and Sadock's Synopsis of Psychiatry: Behav ioral Sciences/Clinical Psychiatry. Philadelphia, Pennsylvania:Lippincott Williams \& Wilkins; 2016. 
5. Pompili M, Girardi P, Ruberto A, Tatarelli R. Suicide in borderline personality disorder: A meta-analysis. Nordic Journal of Psychiatry. 2005; 59(5):319-24.

6. Bradley R, Conklin CZ., Westen D. Borderline personality disorder. In: O’Donohue W, Fowler K, Lilienfeld S, (Eds.). Personality disorders: Toward the DSM-V. Thousand Oaks, CA: Sage; 2007. P.167-201.

7. American Psychiatric Association. Diagnostic and Statistical Manual of Mental Disorders. 5th Edition. USA: American Psychiatric Publishing. 2013. P.991.

8. Gunderson JG, Links P. Borderline Personality Disorder: A clinical guide. 2nd ed. Washington DC: American Psychiatric Press, Inc: 2008.P.416.

9. Sansone RA, Sanson LA, Borderline personality and criminality. Psychiatry (Edgmont) 2009;6(10):16-20.

10. Keuroghlian AS, Zanarini MC. Lessons learned from longitudinal studies of personality disorders, Personality disorders: Toward theoretical and empirical integration in diagnosis and assessment. American Psychological Association 2015:145-61.

11. Zanarini MC, Frankenburg FR, Reich DB, Silk KR, Hudson JI, McSweeney LB. The subsyndromal phenomenology of borderline personality Disorder: A 10-year follow-up study. Am J Psychiatry 2007;164(6):929-35.

12. Mokhtari S, Shariat SV, Ardebili ME, Shalbafan M. Iranian students' attitudes toward premarital sex, marriage, and family in different college majors. J Am Coll Health. 2020 Jul 16:1-9.

13. Eissazade, N., Hemmati, D., Ahlzadeh, N., Shalbafan, M., Askari-Diarjani, A., Mohammadsadeghi, H., \& Pinto da Costa, M. (2021). Attitude towards migration of psychiatric trainees and early career psychiatrists in Iran. BMC medical education, 21(1), 1-7.

14. Bellino S, Bozzatello P, Bogetto F..Combined treatment of borderline personality disorder with interpersonal psychotherapy and pharmacotherapy: predictors of response. Psychiatry Res. 2016 Jun 30;240:151-156

15. Starcevic V, Janca A.Pharmacotherapy of borderline personality disorder: replacing confusion with prudent pragmatism. Curr Opin Psychiatry. 2017 Oct 11

16. TANESI, Patrícia Helena Vaz; YAZIGI, Latife; FIORE, Maria Luiza de Mattos and PITTA, José Cássio do Nascimento. Adherence in the treatment of borderline personality disorders. Estud. psicol. (Natal) [online]. 2007, vol.12, n.1, pp.71-78.

17. Shariati B, Shabani A, Ariana-Kia E, Ahmadzad-Asl M, Alavi K, Behbahani ZM, et al. Drug attitude inventory in patients with bipolar disorder: Psychometric properties. Iranian Journal of Psychiatry and Behavioral Sciences. 2018;12(3):e9831.

18. Asadi, M., Rashedi, V., Khademoreza, N., Seddigh, R., Keshavarz-Akhlaghi, A. A., Ahmadkhaniha,H., ... Shalbafan, M. (2021). Medication Adherence and Drug Attitude Amongst Male Patients with the Methamphetamine-Induced Psychotic Disorder After Discharge: A Three Months Follow Up Study. Journal of Psychoactive Drugs, 1-7. 
19. C.M. Sperber, S.R. Samarasinghe, G.P. Lomax, An upper and lower bound of the medication possession ratio, Patient Prefer. Adherence. 11 (2017) 1469-1478.

20. Zamanzadeh V, Ghahramanian A, Rassouli M, Abbaszadeh A, Alavi- H. Design and implementation content validity Study: development of an instrument for measuring patient-centered communication. J Caring Sci. 2015;4(5):165-78.

21. zarei G, Rahimian Boogar I, Moazedian A, jahan A. Improvement of borderline personality disorder at different time frames of transference focused psychotherapy: a case report. Stud Med Sci. 2020; 31 (4):255-266.

22. Zargar, Y., Sajadi, S. F., Mehrabizadeh Honarmand, M., \& Arshadi, N. (2014). Validation of the borderline personality features scale for children on students in Shiraz. The Journal of Urmia University of Medical Sciences, 25(4), 338-352.

23. Soltaninejad, Abdollah, Ashtiani Ali Fathi, Khodabakhsh Ahmadi, Emad Yahaghi, Alireza Nikmorad, Rohollah Karimi, And Atefe Abdolmanafi. "Structural equation model of borderline personality disorder, emotion-focused coping styles, impulsivity and suicide ideation in soldiers." (2013): 176182.

24. Azadforouz S, Shabani A, Nohesara S, Ahmadzad-AsI M. Non-compliance and related factors in patients with bipolar I disorder: A six month follow-up study. Iranian Journal of Psychiatry and Behavioral Sciences. 2016;10(2).

25. Timäus, C., Meiser, M., Bandelow, B., Engel, K. R., Paschke, A. M., Wiltfang, J., \& Wedekind, D. (2019). Pharmacotherapy of borderline personality disorder: what has changed over two decades? A retrospective evaluation of clinical practice. BMC psychiatry, 19(1), 1-11. 